\title{
Bladder cancer and occupational exposure to leather
}

\author{
L D MARRETT, ${ }^{1}$ P HARTGE, ${ }^{2}$ AND J W MEIGS ${ }^{1}$
}

From the Connecticut Cancer Epidemiology Unit, ${ }^{1}$ Department of Epidemiology and Public Health, Yale University, New Haven, CT, and Environmental Epidemiology Branch, ${ }^{2}$ National Cancer Institute, Bethesda, $M D, U S A$

ABSTRACT A large case-control study of bladder cancer (2982 cases; 5782 controls) included infor- $\overrightarrow{\vec{\omega}}$ mation about occupational exposure to leather. Occupational histories of exposed white study ${ }^{\omega}$ subjects were reviewed and 150 were determined to have had "true" on the job exposure to leather. The odds ratio estimate (OR) of bladder cancer associated with such exposure in white subjects 3 $(n=8063)$ was $1.4(95 \%$ confidence limits $=1.0,1.9)$ after adjustment for sex, age, and cigarette $\omega$ smoking. The risk was highest in those first employed in a leather job before 1945, although no: dose-response relation with duration of leather employment was found. Subjects employed in "dusty" leather jobs had a slightly higher risk than those with other types of leather jobs. Our results 은 are consistent with reports of an increased risk of bladder cancer associated with exposure to $\vec{T}$ leather. Although the agents responsible have not been identified, our findings of an increased risk ${ }_{\sigma}^{\Phi}$ associated with exposure in the earlier years of this century and in dusty jobs suggest that leather dusts may be important.

An excess risk of bladder cancer associated with employment in leather or leather product industries or occupations has been consistently reported in epidemiological studies of varying types conducted in different locations over the years. ${ }^{1-8}$ There has, however, been little consistency in the particular types of jobs associated with this increased risk.

The National Survey of Environment and Health (NSEH) was conducted during 1978-9 in ten areas of the United States, and many bladder cases and controls were interviewed. The purpose of the study was to clarify the roles of a variety of putative risk factors for bladder cancer, particularly the use of artificial sweetners. This report presents the analysis of leather exposure data abstracted from the detailed job history taken for each subject in the study.

\section{Materials and methods}

The design of the NSEH and the characteristics of the study subjects have been described elsewhere. ${ }^{910}$ Briefly, it included all new cases of bladder cancer diagnosed between the ages of 21 and 84 during a 12 month period around 1978 in ten areas of the United States (the states of Connecticut, Iowa, New Jersey, New Mexico, and Utah and the metropolitan areas of Atlanta, Detroit, New Orleans, Seattle, and San

Accepted 15 July 1985
Francisco, all of which had population based tumefr registries in the Surveillance, Epidemiology, and Edo Results (SEER) network, with the exception of News Jersey). Controls were selected by random digito dialling (those aged 21-64) or from Health Carẽ Financing Adminstration (HCFA) files (those aged 65 and over) to have the age distribution expected for $\overrightarrow{5}$ the cases with a two to one control to case ratio in alB areas except Detroit (where it was one to one). Personal interviews solicited information about a num? ber of lifestyle factors including the use of tobacco, coffee, artificial sweetners, and hair dyes and ans occupational history that included questions about on the job exposures. Respondents were asked to pro 3 . vide details of industry and duties and materials to which they were exposed for each job of six of more months' duration.

Response rates were high $(73 \%$ of eligible cases? $75 \%$ of controls aged $21-64 ; 82 \%$ of controls ageos 65-84) and interviews were completed with 2982 sub jects with bladder cancer and 5782 controls. ${ }^{10}$ Alto $N$ gether 386 study subjects reported that they had either worked in a leather industry, had a job working with leather, or had on the job exposure to leather $\sigma$ Since a risk of bladder tumours may arise from contact with dye stuff chemicals, reported exposures to either artificial or natural leather were included? among job related "leather" exposures. Based on a review of the original questionnaires, conducted with 
Table 1 Occupational leather exposure according to sex and type of study subject, bladder cancer cases and controls(whites only); 10 geographic areas of the USA, 1978

\begin{tabular}{lllllll}
\hline $\begin{array}{l}\text { Leather } \\
\text { exposure }\end{array}$ & \multicolumn{2}{l}{ Male } & & \multicolumn{2}{l}{ Female } & Total \\
\cline { 2 - 3 } \cline { 5 - 6 } & Cases & Controls & & Cases & Controls & \\
\hline Never & 2065 & 3821 & & 677 & 1350 & 7913 \\
Ever & 51 & 71 & & 12 & 16 & 150 \\
Total & 2116 & 3892 & & 689 & 1366 & 8063 \\
\hline
\end{tabular}

Ever exposed means employment in a leather job for six months or more.

out knowledge of case-control status, 163 subjects (66 cases and 97 controls) were considered to have had "actual exposure to leather." The remaining $223 \mathrm{had}$ white collar, security, maintenance, or other unexposed jobs working for employers in the leather industry. Since working conditions among those of non-white races probably differed from conditions among whites and since there were too few exposed non-whites $(n=13)$ for separate analysis, the analysis was restricted to the 8063 white study subjects.

Leather exposure has been quantified on a variety of dimensions: firstly, ever never exposed, whereby "ever" is defined to be six or more months' employment in a job with leather exposure as determined by our questionnaire review; secondly, duration of employment in such jobs; thirdly, calendar year of first employment in a job with leather exposure; and, finally, probable exposure to leather dust. Probable exposure to leather dust was determined by one of us (JWM), an occupational health physician, based on his knowledge of work environments and on the job titles and duties reported by the subjects; he was unaware of whether any title or duty pertained to a case or a control.

Odds ratio estimates have been computed for the different categories of leather exposure adjusted for sex, age (21-44, 45-64, 65-84), and smoking habit (ever or never smoked cigarettes for six months or more) using the method of maximum likelihood in the statistical analysis system (SAS) procedure FUNCAT, which carries out log linear modelling. ${ }^{11}$
In addition, unadjusted odds ratios were estimated by the cross product ratio, which is also a maximum likelihood estimator. Ninety five per cent confidence limits (CL) were estimated asymptotically, assuming that the logarithm of the odds ratio estimate is normally distributed.

\section{Results}

One hundred and fifty whites (122 men, 28 women) had worked with leather (table 1). Both sexes had raised risks of bladder cancer associated with exposure to leather, although sex specific unadjusted odds ratios do not differ significantly from one. The sex, age, and smoking adjusted relative risk is 1.4 with $95 \%$ confidence limit (CL) 1.0, 1.9; the unadjusted odds ratio estimate for both sexes combined is also 1.4 , suggesting that adjustment is not important for estimating this effect. The excess risk is confined to those aged 65 and over where the unadjusted odds ratio estimate is 1.8 with $95 \% \mathrm{CL}$ which exclude one (table 2). Although not shown, both sexes had raised risks in the older age group (65-84); in the younger age group both sexes had risks below but close to one.

To look at calendar time of exposure, we initially divided the data into three periods of first employment in a leather job: pre-1920, 1920-44, and 1945 or later. Adjusted odds ratio estimates for these three periods were $1.5,1.4$, and 1.2 respectively; CL all included one. Since the first two periods had similar risks, we combined them to create two first employment periods for the purpose of examining the effect of duration of employment. There is a slightly higher risk among those who were first employed in a leather related job before 1945 (with an odds ratio of 1.4; CL $=1 \cdot 0,2 \cdot 1$ ) than in those first exposed later (table 3 ). For both periods, shorter employment produced a higher risk than longer duration; this is true also for each sex separately. The overall estimate of risk by duration of employment, combining the two employment periods, is $1.7(95 \%$ CL $1.1,2 \cdot 7)$ for leather employment of less than five years duration; 0.9 for 5-14 years; and $1 \cdot 1$ for 15 years or more.

Table 2 Odds ratio estimates (unadjusted) for occupational leather exposure according to age group at diagnosis, bladder cancer cases and controls (whites only); 10 geographic areas of the USA, 1978

\begin{tabular}{|c|c|c|c|c|c|}
\hline \multirow[t]{3}{*}{ Age group } & \multicolumn{5}{|c|}{ Leather exposure } \\
\hline & \multicolumn{2}{|l|}{ Never } & \multicolumn{2}{|l|}{ Ever } & \multirow[t]{2}{*}{$O R(95 \% C L)$} \\
\hline & Cases & Controls & Cases & Controls & \\
\hline $21-84$ & 2742 & 5171 & 63 & 87 & $1.4(1.0,1.9)$ \\
\hline $\begin{array}{l}21-64 \\
65-84\end{array}$ & $\begin{array}{l}1246 \\
1496\end{array}$ & $\begin{array}{l}2243 \\
2928\end{array}$ & $\begin{array}{l}20 \\
43\end{array}$ & $\begin{array}{l}39 \\
48\end{array}$ & $\begin{array}{l}0.9(0.5,1.6) \\
1.8(1.2,2.7)\end{array}$ \\
\hline
\end{tabular}

$\mathrm{OR}=$ Unadjusted odds ratio estimate.

$\mathrm{CL}=$ Confidence limits. 
Table 3 Odds ratio estimates (adjusted) for occupational exposure to leather by year of first employment in a leather job and $\overline{\underline{\alpha}}$ duration of such employment, bladder cancer cases and controls (whites only); 10 geographic areas of the USA, 1978

\begin{tabular}{|c|c|c|c|c|}
\hline $\begin{array}{l}\text { Year of first } \\
\text { leather job }\end{array}$ & $\begin{array}{l}\text { Duration of leather } \\
\text { employment (years) }\end{array}$ & Cases & Controls & $O R(95 \% C L)$ \\
\hline Before 1945 & $\begin{array}{c}\text { Any }(\geqslant 0.5) \\
<5 \\
\geqslant 5 \\
\text { (Unknown) }\end{array}$ & $\begin{array}{l}47 \\
23 \\
22 \\
(2)\end{array}$ & $\begin{array}{l}64 \\
26 \\
38 \\
(0)\end{array}$ & $\begin{array}{l}1.4(1.0,2.1) \\
1.7(0.9,3.0) \\
1.1(0.6,1.9)\end{array}$ \\
\hline $\begin{array}{l}1945 \text { or later } \\
\text { (Unknown) }\end{array}$ & $\begin{array}{c}\text { Any }(\geqslant 0.5) \\
<5 \\
\geqslant 5 \\
\text { (Unknown) }\end{array}$ & $\begin{array}{r}14 \\
10 \\
4 \\
(2)\end{array}$ & $\begin{array}{l}22 \\
10 \\
12 \\
(1)\end{array}$ & $\begin{array}{l}1.2(0.6,2 \cdot 4) \\
1.7(0 \cdot 7,4 \cdot 2) \\
0.7(0.2,2 \cdot 1)\end{array}$ \\
\hline
\end{tabular}

OR = Odds ratio estimate, adjusted for age (3 groups), sex, and cigarette smoking (ever never).

$\mathrm{CL}=$ Confidence limits.

Table 4 Distribution of job titles among those with occupational leather exposure by sex and type of study subject, bladder cancer cases and controls (whites only); 10 geographic areas of the USA, 1978

\begin{tabular}{lrc}
\hline $\begin{array}{l}\text { Job title ("Ever } \\
\text { worked as...")* }\end{array}$ & Cases & Controls \\
\hline Shoemaker & & \\
Sewing machine operator & 24 & 26 \\
Cutter & 6 & 3 \\
Glove, purse, beltmaker & 3 & 11 \\
Car upholsterer & 3 & 9 \\
Pieceworker & 0 & 3 \\
Gluer & 0 & 2 \\
Packer & 0 & 3 \\
Operator & 7 & 1 \\
Tanner & 2 & 12 \\
Labourer & 2 & 4 \\
Other & 14 & 2 \\
Total job titles & 69 & 20 \\
(Total no of individuals) & $(63)$ & 96 \\
\end{tabular}

* Since some had more than one job title involving leather exposure there are more job titles than number exposed.

Table 4 shows the distribution of the "leather exposed" according to leather job title. There are more job titles than workers because each individual could have held more than one leather related job; however, the small differences between numbers of jobs and workers implies that few people did so. The largest occupational group is shoemakers. Althouglo most shoemakers are male, the relative excess of cases over controls was evident in both sexes. The "other" category includes such jobs as bookbinders, leather carvers, and hide cleaners. There is no over represen 6 tation of tanners in the case group.

Those who had ever worked as shoemakers, sewing? machine operators, cutters, beltmakers, or car uphol ${ }^{-}$ sterers or whose reported duties included stitching $\mathbb{D}^{\mathbb{D}}$ cutting, or buffing leather were considered to have at greater potential for exposure to leather dusts than those in other leather jobs; shoemakers and belt, purse, and glove makers were also included in thiso group unless their only specified duties (mouldipg; glueing, assembling, for example), were thought to involve dust. Table 5 shows the results of com paring this group with those with no on the job exposure to leather; each sex separately had odds๊ ratios similar to those shown. Those who worked in jobs with potential dust exposure had a raised odds ratio that does not quite achieve statistica significance, although no dose-response relation with duration of exposure is evident. The excess risk asso ciated with exposure to leather dust was confined to those first exposed before 1945.

Table 5 Odds ratio estimates (unadjusted) for occupational leather dust exposure* by year of first employment and duration 3 of employment in such jobs, bladder cancer cases and controls (whites only); 10 geographic areas of the USA, 1978

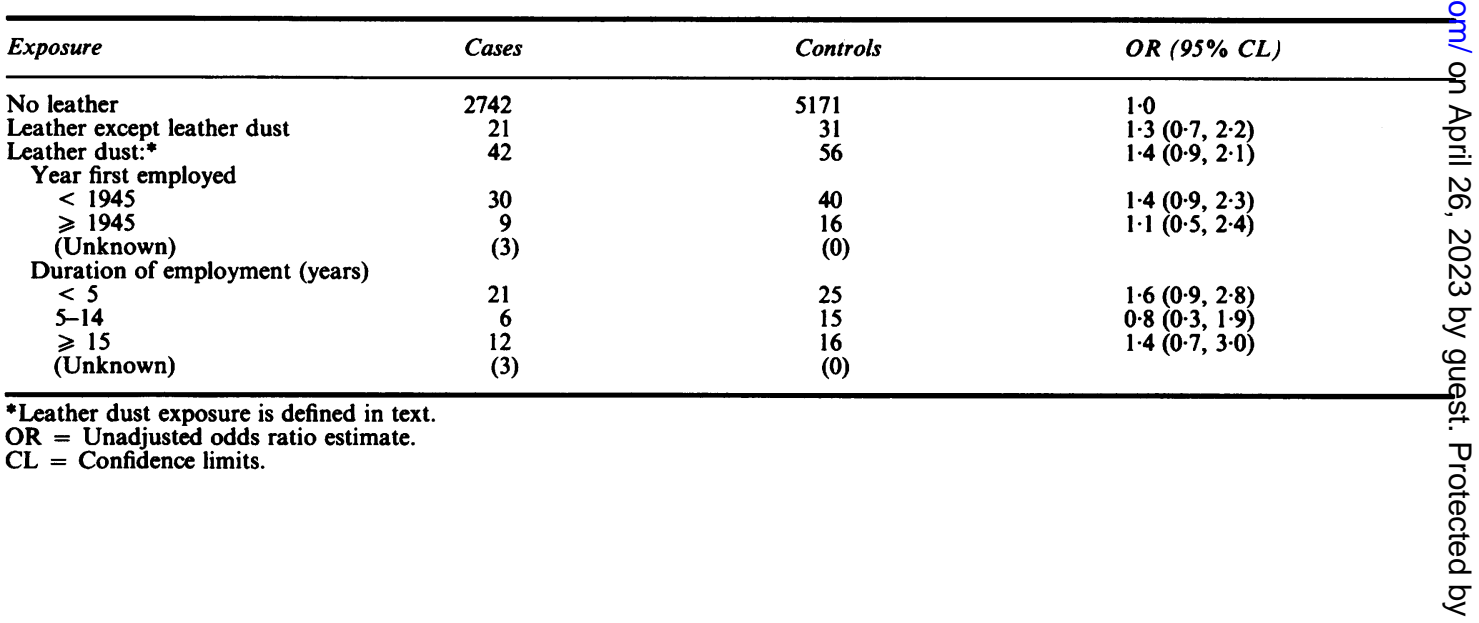




\section{Discussion}

Several studies have reported associations between bladder tumours and a history of working with leather or the leather industry in several countries. ${ }^{1-8}$ The associations with occupations in which leather is named have occurred so often that they seem unlikely to have recurred by chance alone. Nevertheless, there have been no clear lines to connect cause and effect. Leather manufacture, tanning, leather dressing, curriers, shoe hands, shoe makers and repairers, labourers in leather and leather products, cobblers, and artificial leather product manufacture have each figured in one or more significant positive associations. But there has been little consistency in the job titles positively associated with bladder cancer risk except for some relation to leather.

A review of the processes and chemicals used in tanning leather indicates that high risks of bladder tumours probably do not originate in this part of the leather industry ${ }^{12}$; our results support this, although there were few tanners in our study. The observed risks may have occurred in the finishing processes. Many types of leather, both natural and artificial, are dyed $^{13}$ and some dyes, especially dye intermediates, are bladder carcinogens. Benzidine based dyes have been shown to contain small amounts of unreacted benzidine. ${ }^{14}$ Thus at least one mechanism has been shown for a bladder carcinogen to be present in dyed leather. Direct contact in the dyeing process or exposure by inhalation or perhaps skin deposits of dyed leather dusts could also cause exposure in sewing, cutting, handling, or polishing leather, leather products, or artificial leather. In our study ten leather exposed cases and 12 controls reported exposure to dyes. This, however, would not include those with indirect exposure to dye through leather dusts or handling of leather products. We did find raised risks in those with probable relatively heavy exposure to leather dusts.

One issue raised by studies that have shown negative or non-significantly positive associations between bladder cancer and leather exposures-for example, in Leeds, England, ${ }^{15}$ and Finland ${ }^{16}$-is that the working conditions that resulted in the increased risk of bladder tumours may have changed over time, with current hazards less than those earlier in the century. The ages of the patients with leather related bladder tumours provide some support for this. Although Cole et al did not present age related bladder tumour risks by occupation, leather exposures were relatively common among the occupations they recorded. ${ }^{6}$ They probably contributed substantially to occupation related attributable risk estimates which were highest in men aged 60-74, somewhat less among 75-89 year olds, and low in men aged 20-59.
Viadana et al showed that risks of bladder cancer were much greater in men over $60 .{ }^{17}$ Both studies took account of smoking habits. In our study also the odds ratio estimates were highest for those aged 65-84 and were significantly raised.

It is reasonable to suppose that the older leather workers who developed bladder tumours had usually begun that occupation before the younger ones. The NSEH data set provided us with an opportunity to test the hypothesis that an earlier date of first occupational exposure to leather might be related to a higher risk of bladder tumours than later exposure. The end of the second world war marked an acceleration in efforts to improve working conditions through application of industrial hygiene standards, and we found that the risk of bladder tumours was higher in those first employed in a leather job before 1945. In those with probable exposure to leather dusts the difference in risk between pre- and post-1945 exposure was even greater.

This study could not identify with precision the actual exposures that those in leather jobs experienced. Whereas it is fairly certain that all those classified as exposed to leather on the job did actually work with leather, the further breakdown into those with probable or improbable leather dust exposures is much less certain, although we used both job title and reported duties to make this categorisation. Also, the effects of exposure to artificial and natural leather could not be analysed separately due to lack of specificity in the data.

This study attempted to identify all newly diagnosed cases of bladder cancer in study areas and to select controls who were representative of the same population but of similar age sex distribution to the cases. Concerted efforts to interview all eligible subjects resulted in high response rates and interviewers were generally not aware of the case-control status of a subject. No proxy interviews for those who were dead or ill were permitted. Data quality was carefully monitored: routine editing for errors and omissions was performed; responses were validated through brief telephone re-interviews of $15 \%$ of respondents on a few key questions; detailed coding instructions were followed; and standardised verification procedures for coded data were used. Thus high standards were maintained throughout the study in order to minimise effects of bias due to selection or misclassification.

In addition, since examination of the relation between bladder cancer and exposure to leather was only one of many study objectives and was unlikely to have been widely known among subjects or interviewers, and since interviewing, abstracting of details on leather jobs, and determining probable exposure to leather dust were all done without knowledge of 
case-control status, it is unlikely that significant bias due to differential determination of leather exposure between cases and controls occurred.

The lack of dose-response relation in terms of duration of leather employment is puzzling. Since the $\mathbf{9 5 \%}$ confidence intervals overlap for various employment durations, it may be that the level of risk is actually independent of duration. Or it may be that our methods and measures are not sensitive enough to identify the true pattern of risk. For example, it may be that intensity of exposure, which cannot be directly quantified from the study data, is the more important determinant of risk, or that unidentified confounding factors exist.

The question of the exact nature of the relation between leather work and bladder cancer needs further clarification through more detailed investigations. Changes in manufacturing methods and improvements in working conditions make it doubtful that significant excess numbers of bladder tumours would be found in conventional epidemiological surveys. Nevertheless, detailed chemical analyses of manufacturing processes and associated biological monitoring of workers in specific jobs with defined exposures to leather, including dusts and dyes, could test the hypothesis that bladder carcinogens can gain access to the body through dusts.

This study was sponsored by the US Food and Drug Administration, National Cancer Institute, and Environmental Protection Agency. Connecticut investigators were supported by contracts NO1 CP 33235 and NO1 CP 61002 from the National Cancer Institute, by research grant CA 26692 from the National Bladder Cancer Project of the National Cancer Institute, and by a National Health Research Scholar award to Dr Marrett from Health and Welfare Canada.

Requests for reprints to: Dr LD Marrett, Ontario Cancer Treatment and Research Foundation Epidemiology Research Unit, Department of Preventive
Medicine and Biostatistics, Faculty of Medicine, Uni- $\overline{\bar{\alpha}}$ versity of Toronto, Toronto, Ontario M5S 1A8, Can- $\frac{2}{2}$ ada.

\section{References}

${ }^{1}$ Henry SA, Kennaway NM, Kennaway EL. The incidence of cance of the bladder and prostate in certain occupations. J Hyg (Lon $\bar{\sigma}$ don) 1931;31:125-37.

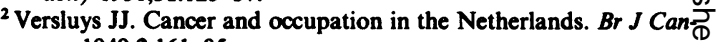
cer 1949;3:161-85.

${ }^{3}$ Registrar General. Decennial supplement, England and Wales 19510 Occupational mortality tables, part II. Vol 2. London: HMSO, 1958.

${ }^{4}$ Guralnick L. Mortality by occupation and cause of death among men20-64 years of age: United States, 1950. Vital statistics-specia $\vec{\omega}$ reports. Vol 53, No 3. Washington: US Pub Health Service: USN Government Printing Office, 1963.

${ }^{5}$ Wynder EL, Onderdonk J, Mantel N. An epidemiologica investigation of cancer of the bladder. Cancer 1963;16:1388-407:

${ }^{6}$ Cole P, Hoover R, Friedell GH. Ocupation and cancer of the lowexw urinary tract. Cancer 1972;29:1250-60.

${ }^{7}$ Ohno Y, Aoki K, Shimizu H, Tominaga S. Geographic epico demiology of bladder cancer deaths in Japan. Acta Urologica Japan 1979;25:121-32.

${ }^{8}$ Decoufle P. Cancer risks associated with employment in the leatherand leather products industry. Arch Environ Health 1979;34:33-7.

${ }^{9}$ Hoover RN, Stasser PH. Artificial sweetners and human bladder cancer. Lancet 1980;i:837-40.

${ }^{10}$ Hartge P, Cahill JI, West D, et al. Design and methods in a multi center case-control interview study. Am J Public Health 1984;74:52-6.

11 Breslow NE, Day NE. Statistical methods in cancer research. Vọl. The analysis of case-control studies. Lyon: International Ageyp for Research on Cancer, 1980. (IARC scientific pub No 32. $F$. O

${ }^{12}$ O'Flaherty F, Stubbings RL. Leather. In: Kirk-Othmer encycloge dia of chemical technology. 2nd ed. New York: Interscience $\overline{\bar{O}}$ 1967:303-43.

${ }^{13}$ Ehrich FF. Pigments. In: Kirk-Othmer encyclopedia of chemicak technology. 2nd ed. New York: Interscience, 1968:555-89.

${ }^{14}$ Boeniger MF, Stein HP, Choudhary G, Neumeister CE. Residua $\overrightarrow{\bar{\sigma}}$ benzidine in imported and domestic benzidine dyes. Toxicol LetIS 1981;9:415-20.

${ }^{15}$ Anthony HM, Thomas GM. Tumors of the urinary bladder: an analysis of the occupations of 1030 patients in Leeds, England? JNCI 1970;45:879-95.

${ }^{16}$ Tola S, Tenho M, Korkala ML, Jarvinen E. Cancer of the urinary bladder in Finland: association with occupation. Int. Arch Occup Environ Health 1980; 46:43-51.

${ }^{17}$ Viadana E, Bross IDJ, Houten L. Cancer experience of men. exposed to inhalation of chemicals or to combustion products. $\mathcal{P}$ Occup Med 1976;18:787-92. 